\title{
Is it possible to avoid pyrrolizidine alkaloid contamination in equine herb containing nutraceuticals?
}

\author{
Bianca Schwarz' and Gabriele Alber² \\ 1 Pferdeinternist - Dr. Bianca C. Schwarz, DipECEIM, Bei der Taffingsmühle 1, 66740 Saarlouis, Germany \\ 2 Navalis ${ }^{\circledast}$ nutraceuticals GmbH, Echterdinger Str. 57, 70794 Filderstadt, Germany
}

\begin{abstract}
Summary: Pyrrolizidine alkaloids (PA) are toxic for horses. Not only herbal teas also compound feed products for equids have tested positive for PA contamination. Nutraceuticals for horses are used for their constitutional effects regarding different organ systems, for example the liver. Especially in nutraceuticals used for their hepatoprotective and regenerative effects a high PA content would be a disadvantage. The present article aims to discuss the problems associated with demanding a PA-free nutraceutical and elucidates adapting the HACCP concept with regards to the European Medical Association's recommendations with the aim of an "as low as reasonably achievable" PA contamination (ALARA concept). In conclusion, the knowledge about the risk of PA contamination should prompt suppliers of herbs as well as manufacturers of herb-based products to voluntarily implement regular quality control measures within their Code of Practice and HACCP concept to minimize PA contamination.
\end{abstract}

Keywords: horse, nutraceuticals, pyrrolizidine alkaloid contamination, herb quality

Citation: Schwarz B., Alber Gabriele (2021) Is it possible to avoid pyrrolizidine alkaloid contamination in equine herb containing nutraceuticals? Pferdeheilkunde 37, 118-122; DOI 10.21836/PEM20210202

Correspondence: Dr. Bianca C. Schwarz, Bei der Taffingsmühle, D-66740 Saarlouis; schwarz@pferdeinternist.de

Submitted: November 20, 2020 Accepted: January 5, 2021

\section{Introduction}

Pyrrolizidine alkaloids (PA) are secondary plant metabolites, which have hepatotoxic, mutagenic and cancerogenic effects (Bodi et al. 2014, Schulz et al. 2015). Humans but also different animal species including horses can suffer acute or chronic intoxications after ingestion of PAs (Bodi et al. 2014, Rückert et al. 2019). For a long time, it has been known, that ingestion of PA-containing ragwort (Senecio jacobaea) leads to irreversible, cumulative lesions in horses' livers with typical histopathological appearance ("Ragwort poisoning") in some cases progressing to liver failure (Caloni et al. 2015).

Not only herbal teas and honey have been found to be contaminated with PA (Bodi et al. 2014), also medicinal teas licensed as medicinal products (Schulz et al. 2015) and compound feed products for equids have tested positive for PA (Rückert et al. 2019). Some of the tested equine compound feeds but also some medicinal teas contain as much PAs to exceed current recommendations (Schulz et al. 2015, Rückert et al. 2019). Rückert et al. (2019) found PA levels exceeding the calculated maximum tolerable levels in $43 \%$ of samples from German equine compound feeds. They claim that PA contamination is mainly due to alfalfa or herbs (Rückert et al. 2019). To the authors' knowledge no studies have been performed looking at PA contamination of herb-based nutraceuticals and feed supplements for horses.

In equine medicine, nutraceuticals or feed supplements are commonly used in horses with various diseases, e.g. renal or liver disease, gastrointestinal problems, or endocrine/metabolic diseases. Per definition complementary feed is a compound feed, which has a high content of certain substances, but which is sufficient for a daily ration only if used in combination with other feed. Feed intended for particular nutritional purposes means feed, which can satisfy a particular nutritional purpose by virtue of its particular composition of method of manufacture, which clearly distinguishes it from ordinary feed (Chapter 1 (i) and (o) of Regulation (EG) 767/2009). The term nutraceutical is currently an umbrella term for feed, which is supposed to have a defined health-promoting, either therapeutic or prophylactic, effect, but is not an approved drug. Legally nutraceuticals are currently regarded as feed supplements.

Different herbs and plant materials are utilised depending on their pharmacological properties. Nutraceuticals for horses with liver disease are supposed to help liver regeneration. Therefore it makes sense to have feed supplements and nutraceuticals without or minimal PA contamination to not further impair liver function

The levels of PA found in most analysed products, e.g. honey or herbal teas are insufficient to cause an acute intoxication in humans, but if they are frequently ingested in quantities that exceed the maximum daily intake they might be a contributing factor to chronic disease (Moreira et al. 2018). The same is probably true for horses.

At first glance, it looks easy to demand nutraceuticals and feed supplements to be free of PA. But this subject is complex 
and there are multiple problems and intricacies related to this. The aim of the article is to shed light on the role PA contamination plays in the equine diet and on some of the problems the manufacturers face by trying to produce PA free products.

\section{Pyrrolizidine alkaloids}

More than $660 \mathrm{PAs}$ and their corresponding $\mathrm{N}$-oxide forms are known. In plants PA are mainly found as $\mathrm{N}$-oxides. PA $\mathrm{N}$-oxides show the same degree of toxicity as the corresponding free PA and the two are metabolically interconvertible and therefore it is necessary to include both species in the analysis (BfAM, 2016, Rückert et al. 2019).

Concentrations of individual PAs are usually summed to calculate total PA content. In the study by Rückert et al. (2019) the mean PA level in all tested feed products was $171 \pm 311 \mu \mathrm{g} /$ $\mathrm{kg}$. The highest PA levels $(>1200 \mu \mathrm{g} / \mathrm{kg})$ were found in alfalfa containing products, one herb containing feed product had $>800 \mu \mathrm{g} / \mathrm{kg}$. Even in botanical raw materials used for herbal medicinal products PA contamination has been found, exceeding the limit for PA intake by the German federal institute of risk assessment BfR (Schulz et al. 2015, BfAM 2016). Currently, PAs are not mentioned as undesirable substances in animal feed in $\S 8$ of the German Futtermittelverordnung (Feed regulation) referring to Directive 2002/32/EG Annex I.

\section{Oral intake limit and risk assessment}

In horses an oral intake limit of $1 \mu \mathrm{g}$ PA $/ \mathrm{kg}$ bodyweight/day has been recommended (Petzinger 2011 a und Petzinger 2011 b) and was used in the study by Rückert et al. (2019) to perform a risk assessment of PA levels for adult horses. In general, for these intake limits the calculated total PA content of a product is used. But the concept of the calculated total PA content weighs all PAs measured equally, without allowing for different toxicity. But it is well-established, that toxicity of PAs varies a lot depending on the type of PA but also on the individual PA and possibly also by interaction between PAs (Bodi et al. 2014, Dübecke 2016).

Type of PA: PAs can be subdivided into monoester, open chained diester and cyclic diesters (Bodi et al. 2014, Dübecke 2016). The monoesters are the least toxic, the open chain diesters have intermediate toxicity, whereas the cyclic diesters are the most toxic (Bodi et al. 2014, Dübecke 2016).

Individual PAs: From acute toxicity studies and from clinical experience we know that individual PAs show significant differences in toxicity (Rückert et al. 2019). LD50 data (deaths 3 to 7 days after administration associated with severe haemorrhagic liver necrosis) obtained following intraperitoneal administration to male rates are available for many PAs (COT 2008, Cheeke and Shull 1985). For example, LD50 for Europine is $>1000 \mathrm{mg} / \mathrm{kg}$ bodyweight (COT 2008) and compared to Retrorsine and Senecionine, the typical PAs in ragwort, which have LD50s of 34 and $50 \mathrm{mg} / \mathrm{kg}$ bodyweight (COT 2008), it is much less toxic. But the calculated total PA content does not account for this difference in toxicity.
Unfortunately, there are nearly no data regarding the relative toxicity of the individual PAs, which is important for a realistic risk assessment. The studies in laboratory animals and some data obtained from toxicity case reports in humans or other animal species do not provide sufficiently reliable data to be used in establishing a health-based guidance value. There is also a lack of reports in equids regarding toxicity of certain PAs but also specific patterns of PA (Rückert et al. 2019). Even in humans there are major problems with risk assessment due to the high amount of different single PAs, available data regarding toxicology, oral bioavailability, etc. (BfR $2011 / 2013$ ). This led to a transitional risk assessment by the German Federal Institute for Risk Assessment (BfR) with a maximum daily PA intake of $0.007 \mu \mathrm{g} / \mathrm{kg}$ body weight $(0.42 \mu \mathrm{g} / 60 \mathrm{~kg}$ adult), which is not legally binding (BfR $2011 / 2013)$. Currently, the Herbal Medicinal Products Committee at the European Medicines Agency recommends a transitional limit of $1.0 \mu \mathrm{g}$ pyrrolizidine alkaloids per day related to the final product (Steinhoff et al. 2019).

\section{Origin of PAs}

If analysis of a nutraceutical detect PAs, it must be checked if this nutraceutical does contain plants producing PAs. For example, multiple medicinal plants and their preparations used in Traditional Chinese Medicine for humans contain PAs (Roeder 2000).

If there is no PA-producing plant included in the nutraceutical, the measured PA-content is indicating a contamination of herbs with other plants, but in some cases, it is not even known which plants might be responsible (Rückert et al. 2019). But certain PA structures can be directly related to their biological origin, as PA-producing plants belonging to one genus produce a characteristic PA-profile (Molyneux et al. 1979). If one PA producing plant is co-harvested with herbs intended for tea production the PA pattern of the contaminating plant should be detected in the respective herbal tea (Bodi et al. 2014). For example, if heliotridine-type PAs, like Europine, Heliotrine and Lasiocarpine are found, contamination with plant material likely from species of the Boraginaceae family can be suspected, with Heliotropium being the most relevant contaminating species, for example comfrey (Symphytum spp.), cherry pie (Heliotropium arborescens) or lungwort (Pulmonaria officinalis) (Bodi et al. 2014).

It gets more difficult once multiple PA-containing plants are contaminating the product (Bodi et al. 2014).

In the study by Rückert et al. (2019) Lycosamine was the most detected PA, followed by Seneciphylline. In herb containing products Europine and Seneciphylline were the most abundant PAs (Rückert et al. 2019).

Rückert et al. (2019) also tested ragwort and this revealed high amounts of Retrorsine, Senecionine, Seneciphylline and Erucifoline as well as their $\mathrm{N}$-oxides. As ragwort is highly toxic for horses and Retrorsine and Senecionine have shown high toxicity levels in LD50 tests (COT 2008) and belong to the most toxic group, the macro-cyclic diesters, we can assume that these special individual PAs, or at least one of them are highly toxic to horses or the combination of these PAs. 
Former studies indicate that composite herbal supplements are more likely to be contaminated with PAs than supplements containing one major plant ingredient (Mulder et al. 2018).

The next step of the analysis is to check the single ingredients of the nutraceutical to determine the origin of contamination. It has been found that certain plant ingredients or foods are more likely to be contaminated with PA, e. g. fennel and thus fennel tea (Bodi et al. 2014).

\section{Reduction of PA contamination and problems}

PA contaminations are a worldwide problem, because a multitude of plants grow in subtropical but also temperate zones and a broad range of products are affected (Dübecke 2016). The pharmaceutical industry in Germany with the $B A H$ (Bundesverband der Arzneimittelhersteller e.V.) and the BPI (Bundesverband der pharmazeutischen Industrie e.V.) have taken self-regulating measures to investigate possible causes, to increasingly analyse different batches and initiate targeted research. They have also compiled a "Code of Practice" (BAH, BPI 2015, BfAM 2016). The EMA recommends the ALARA concept (as low as reasonably achievable) for the risk management approach concerning the PA contamination of herbal medicinal products (EMA 2016).

Unfortunately for feed there are no clear regulations regarding PAs in Germany. Although chapter 2, article 4 of Regulation (EG) 767/2009 states, that feed must not have a direct adverse effect on animal welfare, PAs are not mentioned as undesirable substances nor is there a legally binding daily intake limit.

Nevertheless the knowledge about the risk of PA contamination should prompt suppliers of herbs and alfalfa as well as manufacturers of herb and alfalfa based equine complementary feed and feed supplements as well as nutraceuticals to investigate the situation regarding their products. They should adapt their Code of Practice by monitoring PA contamination and collecting data and also participate in research projects. The aim is to reduce PA contamination and eliminate peak exposures (Rückert et al. 2019, Steinhoff et al. 2019).

Suggested approach to reduce PA contamination in equine complementary feed, feed supplements and nutraceuticals containing botanical ingredients, like herbs or alfalfa known to be possibly contaminated with PAs:

1. Adapt the HACCP concept regarding the EMA's recommendations with an "as low as reasonably achievable" PA contamination (ALARA concept)

2. Analysis of the supplement and identification of the raw material, which is PA contaminated (Rückert et al. 2019). Worldwide cultivation and collection, but also season-dependent sourcing processes have to be taken into account.

3. Check and demand herb and alfalfa quality: the herb quality is significantly influenced by the effort of the producer/harvester to identify and remove the plants responsible for the contamination from the field. Another important factor is the effort made by the refiner to separate the herbs from other plants, which is a very cost-intensive process, because this has to be done manually. This requires identification of the plants by the workers.

Furthermore, the way of production (organic versus traditional) may be important with respect to the level of PA contamination (Mulder et al. 2018).

4. Include PAs in the list of undesired substances with a maximum content in Directive 2002/32/EG Annex I.

Unfortunately, there are many further obstacles to overcome, for example how to solve the problem with spot contamination in fields, which might lead to extremely variable PA concentrations even in one harvest or batch (Christall 2015). Even regarding analysis of PAs there are discrepancies. BfR and EFSA disagree on the choice of PAs analysed and Therefore some analysis are not comparable (Christall 2015).

\section{PA contamination of equine supplements put into per- spective}

While oral intake limits in human food products are discussed with all the related challenges, PA-containing plants are used for cooking, for example borage or comfrey and as medicinal plants, for example in Traditional Chinese Medicine (Roeder 2000).

The European Medical Agency (EMA) concluded 2016, that the contamination of herbal products with PA is probably not new and PA intake has probably been constant over the last decades. With new sensitive analytical methods, it is now possible to detect very low levels of PAs (EMA 2016).

Risk assessment and model calculation have integrated multiple security factors which leads to the situation that the real risk is probably lower than the calculated risk (Christall 2015). This needs to be communicated and clarified appropriately, without alienating the public (Christall 2015).

The current situation regarding equine nutraceuticals even with ingredients of pharmacopoeia defined quality is comparable to the situation in humans, where medicinal teas licensed as medicinal products contain PAs, some even exceeding current recommendations (Schulz et al. 2015). As suggested, manufacturers are advised to perform rigorous quality control tests in respect of PA contamination as first step to try and minimize PA concentration in their products (Schulz et al. 2015).

As PAs are the most widely distributed natural toxins total eradication of PA-containing plants is not feasible (EMA 2016). Furthermore, its needs to be considered that ragwort has a total PA content of approximately $2 \mathrm{~g} / \mathrm{kg}(2,000,000 \mu \mathrm{g} / \mathrm{kg})$ (Christall 2015). As few as one Senecio plant per hectare in a field of St. John's Wort is sufficient to exceed the limit (Christall 2015, EMA 2016).

Another important fact is, that the diet of horses mostly consists of forage, which, depending on the geographical location, the harvest date and the year, can be massively contaminated by ragwort (Jacobaea vulgaris, Senecio jacobaea) or 
marsh ragwort (Jacobaea aquatica) (Chizzola et al. 2019). For example, in areas with marsh ragwort a total PA content of $100 \mathrm{mg} / \mathrm{kg}$ is easily reached in forage cut in summer, which provides more than 1-3 mg PAs/kg body weight per day to horses (Chizzola et al. 2019). This massively exceeds the recommended oral intake limit of $1 \mu \mathrm{g} \mathrm{PA} / \mathrm{kg}$ bodyweight/ day. For hay up to $14,6 \mathrm{mg}$ total PA content/kg and for hay cubes $54 \mathrm{mg} / \mathrm{kg}$ have been reported (Gottschalk 2016). The PA contamination in compound feed and supplements and nutraceuticals adds to this.

Nevertheless, the knowledge about the risk of PA contamination should prompt suppliers of herbs as well as manufacturers of herb-based products to voluntarily implement regular quality measures with their Code of Practice and HACCP concept to minimize or prevent PA contamination.

\section{Funding}

The study was funded by $\mathrm{Navalis}^{\circledR}$ nutraceuticals $\mathrm{GmbH}$, Echterdinger Str. 57, 70794 Filderstadt, Germany

\section{Conflict of interest statement}

Dr. Bianca Schwarz, DipECEIM is medical advisor of Navalis ${ }^{\circledR}$ nutraceuticals $\mathrm{GmbH}$ and Dr. Gabriele Alber is Managing Director of $\mathrm{Navalis}^{\circledR}$ nutraceuticals $\mathrm{GmbH}$

\section{References}

BAH (Bundesverband der Arzneimittelhersteller e.V.); BPI (Bundeverband der pharmazeutischen Industrie e.V.) (2015): Code of Practice zur Vermeidung und Verringerung von Kontaminationen pflanzlicher Arzneimittel mit Pyrrolizidinalkaloiden

Bodi D., Ronczka S., Gottschalk C., Behr N., Sikbba A., Wagner M., Lahrssen-Wiederholt M., Preiss-Weigert A., These A. (2014) Determination of pyrrolizidine alkaloids in tea, herbal drugs and honey. Food Additives \& Contaminants: Part A. 31 (11), 1886-1895

BfAM (Bundesinstitut für Arzneimittel und Medizinprodukte) (2016): Bekanntmachung zur Prüfung des Gehalts an Pyrrolizidinalkaloiden zur Sicherstellung der Qualität und Unbedenklichkeit von Arzneimitteln, die pflanzliche Stoffe bzw. pflanzliche Zubereitungen oder homöopathische Zubereitungen aus pflanzlichen Ausgangsstoffen als Wirkstoffe enthalten vom 1. März 2016

BfR (Bundesinstitut für Risikobewertung) (2011/2013): Analytik und Toxizität von Pyrrolizidinalkaloiden sowie eine Einschätzung des gesundheitlichen Risikos durch deren Vorkommen in Honig Stellungnahme Nr. 038/2011
Caloni F., Cortinovis C. (2015) Plants poisonous to horses in Europe. Equine Vet. Edu. 27 (5), 269-274

Cheeke P. R., Shull L. R. (1985) Natural Toxicants in Feeds and Poisonous Plants. Westport, Connecticut, The AVI Publishing Compant, Inc.

Chizzola R., Bassler-Binder G., Karrer G., Kriechbaum M. (2019) Pyrrolizidine alkaloid production of Jacobaea aquatica and contamination of forage in meadows of Northern Austria. Grass Forage Sci. 74, 19-28

Christall B. (2015): Pyrrolizidinalkaloide in Lebensmitteln - Aktivitäten des BLL und Positionen der Lebensmittelwirtschaft. 16. BfR-Forum Verbraucherschutz, 3./4. Dezember 2015

COT Statement on Pyrrolizidine Alkaloids in Food, Committee on toxicity 2008: https://COT.food.gov.uk/sites/default/files/COT/ COTstatementpa200806.pdf

Dübecke A. (2016) Pyrrolizidinalkaloide - ein weltweites Problem? https://www.tentamus.com/qsi-de/wp-content/uploads/sites /11/2018/01/65_PR_Duebecke.pdf, Accessed 10.01.2020

European Medical Agency (EMA) Committee on Herbal Medicinal Products (HMPC) (2016): Public statement on contamination of herbal medicinal products/traditional herbal medicinal products with pyrrolizidine alkaloids. 31 May 2016, EMA/HMPC/328782/2016

Gottschalk C. (2016) Toxische Pyrrolizidinalkaloide in der Nahrungskette - Ein Risiko für Mensch und Tier? KELDAT-Ringvorlesung, 08.11 .2016

Molyneux R. J., Johnson A. E., Roitman J. N., Benson M. E. (1979) Chemistry of toxic range plants. Determination of pyrrolizidine alkaloid content and composition in Senecio species by NMR spectroscopy. J. Agric. Food Chem. 27, 494-499

Moreira R., Pereira D. M., Valentao P., Andrade P. B. (2018) Pyrrolizidine Alkaloids: Chemistry, Pharmacology, Toxicology and Food Safety. Int. J. Mol. Sci. 19, 1668; DOI 10.3390 /ijms 19061668

Mulder P. P. J., Lopez P., Castelari M., Bodi D., Ronczka S., Preiss-Weigert A. (2018) These A. Occurrence of pyrrolizidine alkaloids in animal-and plant-derived food: results of a survey across Europe, Food Additives \& Contaminants: Part A 35 (1), 1 18-133

Petzinger E. (2011) Pyrrolizidine alkaloids and seneciosis in farm animals. Part 1: occurrence, chemistry and toxicology. Tierarztl. Prax. Ausg. G Grosstiere Nutztiere 39, 221-230

Petzinger E. (2011) Pyrrolizidine alkaloids and seneciosis in farm animals. Part 2: clinical signs, species-specific sensitivity, food residues, feed contamination, limit values. Tierarztl. Prax. Ausg. G Grosstiere Nutztiere 39, 363-372

Roeder E. (2000) Medicinal plants in China containing pyrrolizidine alkaloids. Pharmazie 55 (10), 711-726

Rückert C., Emmerich I., Hertzsch R., Vervuert I. (2019) Pyrrolizidine alkaloids in commercial feedstuffs for horses. Equine Vet. J. 51 (4), 495-499

Schulz M., Meins J., Diemert S., Zagermann-Muncke P., Goebel R., Schrenk D, Schubert-Zsilavecz M., Abdel-Tawab M. (2015) Detection of pyrrolizidine al.kaloids in German licensed herbal medicinal teas. Phytomedicine 22 (6), 648-656

Steinhoff B. (2019) Pyrrolizidine alkaloid contamination in herbal medicinal products: Limits and occurrence. Food and Chemical Toxicology 130, 262-266 